\title{
A hybrid QFD-based approach in addressing supplier selection problem in product improvement process
}

\author{
Mehdi Rajabi Asadabadi*
}

MEng (cand), University of San Jose-Recoletos, Cebu City, Philippines

CHRON I CLE ABSTRACT

\begin{tabular}{l}
\hline Article history: \\
Received January 62014 \\
Received in Revised Format \\
June 152014 \\
Accepted July 172014 \\
Available online \\
July 242014 \\
\hline Keywords: \\
HOQ \\
Supplier Selection \\
QFD \\
MCDM \\
\hline
\end{tabular}

\begin{abstract}
This paper is about creating a hybrid QFD-based approach in which the best supplier is selected considering changing customer needs. In most previous studies employing a QFD approach, the possibility of changing customer needs is ignored. On the other hand, supplier selection is a challenging problem that could have been addressed by such a QFD. This paper attempts to create a hybrid QFD-based approach in which the internal relations between the elements are considered. It connects the new QFD to suppliers' qualifications to create a hybrid supplier selection process. The best suppliers are selected based on the priorities of customer needs for each level of the product improvement plan. When a product is to be developed, the proposed methodology seems to create an efficient solution for supplier selection problem with respect to quality factors.
\end{abstract}

(C) 2014 Growing Science Ltd. All rights reserved

\section{Introduction}

Over the last few decades, there have been tremendous efforts on improving the competitiveness of the companies by applying various supplier selection strategies (Tidwell \& Sutterfield, 2012; Ramadan \& Schmits, 2006). Supplier selection problem is one of the most challenging decisions to make. There are various factors to be considered before selecting a supplier (Karsak \& Ece, 2012), which play an essential role in meeting the customer needs (Prasad et al., 2012).

QFD has been previously employed to trace the customer needs (CNs) in the supplier selection process (see Tidwell \& Sutterfield, 2012; Ramadan \& Schmits 2006), but the possibility of changing the CNs in a QFD that is observant to the internal relationship between the elements has not been investigated. How to keep the customers happier is a challenging job, but it becomes more complicated when their needs change within preparing the final product. The price suggested by suppliers is essential, but it is not all. Various factors influencing the supplier selection decision has created several methods proposed by numerous researchers (Ho et al., 2011). The objective of this paper is to demonstrate how a hybrid-QFD can be employed to propose a solution to the problem of supplier selection. The hybridQFD is formed based on changing CNs and finds the priorities of product requirements (PRs). The

\footnotetext{
* Corresponding author. Tel: +0063-906-332-2714

E-mail: rajabi@usjr.edu.ph

rajabi689@yahoo.com (M. Rajabi Asadabadi)

(C) 2014 Growing Science Ltd. All rights reserved.

doi: $10.5267 /$ j.ijiec.2014.7.005
} 
supplier selection problem should not be seen as a problem with a fixed answer, but a model should be considered to take the relevant changes into account for supplier selection process. This paper attempts to create a link between selected supplier and changing CNs.

To have the customers satisfied, improving the quality of the product must be kept up. The quality of the product is influenced by the raw materials sent by the suppliers (Dey et al., 2012), so designing a supplier selection process based on CNs seems to be a sufficient guideline. QFD is recognized as an effective approach to determine the most important PRs to improve (Ayag et al., 2013). The House of Quality (HOQ) as the main tool of QFD approach builds a connection between the CNs in the right hand of the HOQ and PRs on the roof of it (Dey et al., 2012). The internal relationship between the elements of HOQ need to be considered and the analytic network process (ANP) is capable of it (Buyukozkan \& Berkol, 2011). In this paper, CNs are connected to PRs by employing a HOQ provided with ANP. The ANP is applied to reduce the complexity of considering the internal relations (Ozaki et al., 2012). The proposed approach connecting the supplier selection problem to the priority of CNs confronts the possibility of changes in CNs during the product improvement process. This fact makes decision makers consider a series of priorities in customer needs instead of a single set. Needs of customers are possible to change for several known and unknown reasons. Since the CNs are changing, the selected suppliers might also change, which sometimes is not desirable, so the decision about improvement plans should be made before starting the supplier selection process.

In comparison to previous papers, the contribution of this paper is as follows. First, considering the possibility of changing the priority of CNs it creates a hybrid QFD-based approach in product improvement process. Second, it employs the results in addressing supplier selection problem. The remainder of this paper is organized as follows. Next part is literature review in which some of previous relevant papers in four categories are studied, 2.1 Quality Function Deployment (QFD), 2.2 The HOQ, 2.3 Application of Decision Methods in QFD, and 2.4 Supplier selection. In section 3, the methodology is presented which its practicability is confirmed by an illustrative example in section 4, then the findings are discussed in section 5, and a conclusion is presented at the end.

\section{2- Literature review}

\section{$2.1 Q F D$}

Quality has been a fixed part in management thinking since 1980s. Quality control was firstly used in manufacturing and inspection area, but soon it spread to all functions of every organization (Jiang et al., 2007). The product improvement plans of an organization are more structured when an approach such as QFD is employed (Gremyr \& Raharjo, 2013). Today, successful applications of using QFD are seen in a wide variety of producing products and services as a powerful tool to address operational decisions (GinnandZairi, 2005). The QFD starts by acquiring CNs and develops by forming tables and charts (Jiang et al., 2007). It is an effective part of total quality management (TQM) (Mehrjerdi, 2010). QFD, as a design tool, is employed within the product improvement process to make the design team capable of a better output (Kavoch et al., 2006). Some researchers such as Mehrjerdi (2010) have pointed out some benefits of applying QFD approach;

- It creates a connection between products and customers

- It encourages forming cross functional teams and effective communications in an organization

- It removes some wastes

- It creates a more accurate database

However, wrong or non-effective application of QFD can reduce or even reverse the benefits of QFD (Mehrjerdi, 2010). An effective use of QFD can result in substantial product improvement along with the CNs and marketplace (Özgener, 2003). One of the most important benefits of QFD is that it creates 
a structural decision making approach instead of an intuitive approach (Kavoch et al., 2006). Since the first applications of QFD, it has been developed by applying different numerical analysis methods and methodologies (Jiang et al., 2007). These areas have been divided by Ho et al. (1999) as follows:

“(1) QFD combined with TRIZ (Russian theory of inventive problem solving), Pugh concept selection, and Taguchi methods, in order to strengthen more the effectiveness of QFD in product design and process design;

(2) QFD combined with different numerical analysis methods, such as fuzzy sets, AHP, and neural network, in order to strengthen more the accuracy of QFD in weight determination and numerical analysis; and

(3) The research of QFD application, such as QFD combined with strategic management and policy management, and QFD's key successful factors in practice".

Study by Kavoch et al. (2006) demonstrates how decision making is affected by the QFD; "Reduction in development cycle time is a well-known benefit of using QFD. QFD increases the efficiency with which decisions are made within the design process in several ways. First, QFD creates an atmosphere of teamwork that provides clear paths of communication to facilitate the decision-making process. Additionally, the cross functional nature of QFD teams brings together representatives from different departments so that each has input into the decisions made. In general, having the right people in the right place at the right time helps make the decision process flow smoothly". Global competitiveness has made the companies look for an effective approach to improve the quality of their goods or services. QFD as a technique of TQM has been increasingly applied to help product improvement process (Ertugrul et al., 2002).

\subsection{House of Quality $(H O Q)$}

The HOQ includes some matrices correlating CNs with PRs (Hauster \& Clausing, 1988). Employing the HOQ for the product improvement process requires finding and evaluating CNs (Zhang \& Wang, 2012) and then the CNs as the entrance of the HOQ must be translated to PRs of the product (Behzadian et al., 2013). By translating the CNs to PRs, the HOQ can be a useful tool for the cross functional team (Liu, 2010). The HOQ, as the main tool of QFD, is a useful tool to evaluate CNs and connect them to the PRs (Kim, 2010). The relationships between CNs and PRs should be evaluated and numbers presenting the strength should be assigned (Kim, 2010). The HOQ can be used separately, but it can be also attached to another process and be used as a design tool (Olewnik \& Kemper, 2008).

According to Lin and Pekkarinen (2011): "HOQ includes six phases: 1. Identify customer requirements (WHATs) and evaluate those weights in the left wall of the house; 2. Compare the competitiveness of the service in the right wall; 3. Translate customer requirements into service design characteristics (HOWs) just below the roof; 4. Define the relationship between WHATs and HOWs in the central deployment matrix or called relationship matrix; 5. Define the relationships between the various service design characteristics in the correlation matrix in the roof; and 6. Design the target values of the service".

The HOQ is used to define the relations between the elements of two different groups of elements such as CNs and PRs. The aim of determining the relations between the elements is to find the most important parameters to improve (Olewnik \& Kemper, 2008). Aside from the relations between the elements of PRs and CNs, there are usually some relations between the elements, internally, which are not seen in the traditional applications of the HOQ. Some elements are supportively or adversely affecting each other. These internal relations also should be seen and considered to have more accurate results (Buyukozkan \& Berkol, 2011). 


\subsection{Application of Decision Methods in QFD}

Making a decision when the attributes are few and there are no interrelations among them is not so difficult, but a structured decision method must be utilized when there are several elements affecting, internally, each other (Nazari et al., 2012). Tsalatsanis et al. (2010) evaluate the intuition contribution and analytical process and come up with a model to cover both of these as a decision making model; "Decision-making is governed by intuition and analytical deliberative process, thus, rational decisionmaking should reflect both formal principles of rationality and intuition about good decisions". Ordoobadi (2012) highlights several factors to be considered in the selection process; "Selection is multidimensional in nature and interdependent relationships exist among various elements. In addition, both quantitative and qualitative factors need to be considered in the evaluation process".

The AHP/ANP recently have been used widely to strengthen the QFD. The AHP has hierarchical structure that is not accounting for the interdependencies. In order to account for the interdependencies of the AHP, the ANP was developed by Saaty (Steiner et al., 2011). ANP presents a framework for observing the effects of internal relations to find the priority of elements that have various effects on each other when the relations are evaluated with respect to a variety of factors. The QFD can be applied as an effective approach to find the priorities of some elements with respect to the weights of some other relevant factors, and it becomes more effective when decision method such as the AHP is applied to create a hierarchy or the ANP to cover the interdependencies (Andronikidis et al., 2009).

Ho et al. (2011) use QFD to translate the company stakeholder requirements into multiple evaluating factors for supplier selection. In their suggested approach for a case study of a company, a QFD approach is employed to translate the company stakeholder requirements into multiple evaluating factors to select the best supplier. Delice and Güngör (2009) attempt to use the MILP model and Kano model for a QFD optimization approach to acquire an optimized solution. In their methodology, MILP model and the Kano model are combined to address the product improvement problem considering the interdependencies. Raharjo et al. (2011) challenge one of the simple, but less seen problems in QFD. They deal with the possibility of changes in CNs. They suggest a solution for changing customer needs since the time of gathering the information until the time that the product is ready to sell. For that purpose, they apply a forecasting technique. QFD with a framework of the AHP is applied by Mayyas et al. (2011) for the process of material selection. They consider a ranking approach for expressing the different competitive materials to optimize the overall design. They apply the AHP analysis to find the importance of raw material for the company. Kim and Kim (2009) deal with the robustness of the priority that is resulted from applying the HOQ. They come up with two indices for measuring it and consider the possible effects of uncertainty in entering data to the HOQ.

Cassandra et al. (2012) also investigate changing CNs: "meeting the rapidly changing and demanding requirements of customers is of the highest importance to product designers and executives around the globe. In recent years, customers have grown accustomed to their own purchasing power granting them nearly-instantaneous product gratification perfectly matched and customized to their individual requirements and specifications with high quality and most importantly, in an almost instant fashion".

\subsection{Supplier Selection}

Supplier evaluation is accounted as a multi-criteria decision making problem (Dey et al., 2012). Micheli (2008) says: "selecting the right supplier is a complex decision made by companies and organizations, with potentially significant impact on the organization's ongoing performance and its ability to obtain the quality products and services. Supplier evaluation and selection are critical activities in the purchasing process, and significantly affect the organization's success. Unless the supplier is properly selected, then strategic alliances, supplier development, and early supplier 
involvement become more difficult to be implemented". Modern management prefers a company to establish a long-term relation with one or only a few suppliers rather than changing the suppliers to ensure mutual understanding and stability. This emphasizes the importance of supplier evaluation and selection (Ordoobadi, 2012).

In the continuous improvement process, not only machining, activities, assembly, inventory level and some other internal factors are affecting, but also selecting the best suppliers must be considered as an important decision problem (Gonzales et al., 2004). Researches, related with supplier selection, are widespread in different areas of the problem. They vary from a company to another company or by time passing. Most researchers are following technical parameters issues in supplier selection process (Tidwell \& Sutterfield, 2012; Chandra \& Grabis, 2003; Pearson \& Ellram, 1995). Researchers have been using different techniques from mixed integer programming and multi-objective programming (Stadtler, 2007; Weber \& Ellram, 1993) to application of the AHP/ANP and Fuzzy theory for supplier selection (Kahraman et al., 2003; Asamoah et al., 2012). Accounting for relations and inner relations between the criteria as well as the objectives makes the ANP-QFD more realistic and more reliable for the selecting process (Ordoobadi, 2012). Jabour and Jabour (2009) analyze environmental factors in supplier selection. "The transformations desired by companies in developing products and processes are related to the capacity of their suppliers to become environmentally fit" (Jabour \& Jabour, 2009).

According to Herbon et al. (2012), instead of working on price reduction, it would be more effective to work on some other processes such as supplier selection to receive the proper raw materials (Herbon et al., 2012). Wu (2009) investigates the effects of uncertainty on supplier selection; "the more flexible a supplier is, the more valuable that supplier is to the buyers in an uncertain environment" (Wu, 2009). The importance of supplier selection is obvious, but unfortunately, it is less seen that an organization employs a structural selection process to find the best supplier (Herbon et al., 2012).

\section{Methodology}

This methodology is organized in two sections. The results of the first section are linked to the second section. The following notations for matrices are used throughout the paper.

\begin{tabular}{ll}
\hline$W_{C P r i}$ & The priority of CNs \\
$W_{C N N}$ & The inner dependencies among CN \\
$W_{P R R}$ & The inner dependencies among PRs \\
$W_{P R-C N}$ & The relations between CNs and PRs \\
$W_{2_{-} C P r i}$ & The priorities of CNs considering the inner dependencies between them \\
$W_{2_{-} P R-C N}$ & The relations between PRs and CNs considering their inner dependencies \\
$W_{A N P}$ & The priority of product parameters considering all the inner and outer dependencies \\
$W_{C P r i} i_{S E Q}$ & A sequence of priorities in CNs \\
$W_{A N P S E Q}$ & The resulted sequence of the priorities in PRs \\
$C_{W}$ ANP st & Column i of matrix $W_{A N P S Q}$ weighted based on how costly step i of improvement plan is \\
$W_{S t e p s}$ & A matrix in which column i presents the importance of PRs for improving to fulfill step i \\
$W_{S-P R}$ & The relations between suppliers and PRs \\
$W_{S W}$ & A matrix in which column i compares the suppliers for the improving to fulfill step i \\
\hline
\end{tabular}

\subsection{Computing $W_{A N P S Q}$}

Firstly, one of the common methodologies, previously applied for combining the ANP and the HOQ by some researchers (Ertugrul et al. 2002; Buyukozkan \& Berkol 2011), is explained and then proposed QFD is replaced with a hybrid-QFD to address the supplier selection problem. Before starting the approach, some information about what the customers want should be gathered. After the information is gathered, they are evaluated and prioritized based on customers expressions by some cross functional groups. The results build the first matrix $\left(W_{C P r i o}\right)$. After that, the PRs are listed. The strongest relation 
is shown with 9 where this number decreases by decreasing the strength of the relations. $\mathrm{W}_{\text {Customer-prioritization }}$ or $\mathrm{W}_{\mathrm{CPri}}$ denotes a matrix which includes customer priorities.

$$
W_{C P r i}=\left[\begin{array}{c}
a_{1} \\
\vdots \\
: \\
a_{n}
\end{array}\right]
$$

The second matrix is $W_{C-N e e d s-N e e d s}\left(W_{C N N}\right)$. This matrix presents the inner dependencies between customer needs. Each of the columns of $\mathrm{W}_{\mathrm{CNN}}$ is acquired separately from a table. The following steps can help to compute column i;

1-Doing the pairwise comparisons between customer needs

With respect to $i^{\text {th }} \mathrm{CNs}$, each $\mathrm{CN}$ is compared to another $\mathrm{CNs}$ one by one. Tables presenting the relations of customer needs with respect to each of them are formed.

2-Computing the importance weights for the table.

3-Placing these weights to $i^{\text {th }}$ column of $\mathrm{W}_{\mathrm{CNN}}\left(a_{1 i}, a_{2 i}, \ldots\right)$

$W_{C N N}=\left[\begin{array}{cccc}a_{11} & . . & . . & a_{1 n} \\ : & . . & . . & : \\ : & . . & . . & : \\ a_{n 1} & . . & . . & a_{n n}\end{array}\right]$

$n:$ the number of customer needs

The above three steps for the PRs are repeated to build $m$ (the number of parameters) tables. Inner dependencies of PRs with respect to each of them should be computed to form the columns of $W_{\text {Product }-R-R}$ or $W_{P R R}$.

$W_{P R R}=\left[\begin{array}{cccc}b_{11} & . . & . . & b_{1 m} \\ \vdots & . . & . . & \vdots \\ : & . . & . . & : \\ b_{m 1} & . . & . . & b_{m m}\end{array}\right]$

$m$ : the number of products parameters

An approach similar to the above approach must be followed to build $W_{\text {Product-R-R }}$ or $W_{P R R}$.

$W_{P R-C N}=\left[\begin{array}{cccc}c_{11} & . . & . . & c_{1 n} \\ : & . . & . . & : \\ : & . . & . . & : \\ c_{m 1} & . . & . . & c_{m n}\end{array}\right]$

Then the supper matrix discussed by Thomas Saaty (Saaty, 1999) is possible to form. The supper matrix suggested by Saaty can be shown in a summarized version as matrix (1).

$$
W=\begin{aligned}
& \text { Goal } \\
& \text { PNS }
\end{aligned}\left[\begin{array}{ccc}
\text { Goal } & \text { CNS } & \text { PRs } \\
0 & 0 & 0 \\
W_{C P r i} & W_{C N N} & 0 \\
0 & W_{P R-C N} & W_{P R R}
\end{array}\right]
$$

$W_{A N P}$ forms by following the steps below;

1-Multiplying matrix $W_{C N N}$ by $W_{C P r i}$, (Eq. 6)

The resulted matrix, $W_{2 \_C P r i}$, presents the customer priorities affected by the inner dependencies between CNs.

2-Multiplying matrix $\mathrm{W}_{\mathrm{PRR}}$ by $\mathrm{W}_{\mathrm{PR}-\mathrm{CN}}$ 
The resulted matrix, $\mathrm{W}_{2 \mathrm{PR}-\mathrm{CN}}$, presents the strength of relations between PRs and CNs affected by the inner relations between them.

3-Multiplying the second computed matrix $\left(\mathrm{W}_{2_{-} \mathrm{PR}-\mathrm{CN}}\right)$ by the first one $\left(\mathrm{W}_{2_{-} \mathrm{CPri}}\right)$, Eq. $(8)$

A prioritized list of PRs (to improve) is resulted and shown by $W_{A N P}$.

$$
\begin{aligned}
& W_{2_{-} C P r i}=W_{C N N} \times W_{C P r i} \\
& W_{2_{-} P R-C N}=W_{\mathrm{PRR}} \times \mathrm{W}_{\mathrm{PR}-\mathrm{CN}} \\
& W_{A N P}=W_{2_{P R}-C N} \times W_{2_{C P r i}} \\
& W_{A N P}=\left[\begin{array}{c}
d_{1} \\
\vdots \\
\vdots \\
d_{m}
\end{array}\right]
\end{aligned}
$$

Matrix $W_{A N P}$ can be used as a good guideline for the product improvement plan. Within the improvement plan a problem turns up; by working on these parameters, customer satisfaction increases, but as soon as the customer satisfaction starts increasing, it creates a possibility of changing the priorities of CNs. In real world experiences, this happens frequently. As an example the evaluation of the cell phone can be considered. The customer needs for the cell phones have been changing over the past few years and they are still changing. Considering this situation, it is realized that if the product parameters were being improved based on above computed matrix (9), it would be possible that some product requirements would be improved more than what they should be. If it happened, that would be wasting considering the fact that the priority of PRs is computed based on the priority of CNs.

The need of a replacing the QFD with a hybrid-QFD is felt now, but the problem is how to find the CNs for forming a hybrid-QFD. For that purpose, there might be different strategies for different companies considering their products, but here two strategies are suggested. In some cases, especially for mass manufacturers, it is possible and economically reasonable to have the parameters improved (on some sample products) for a level, considering $W_{A N P}$. The samples can be submitted or sold to some customers and then a new set of CNs should be obtained (by the same method that the first set of CNs were obtained). While doing this, the company should compute the total needed resources, especially the budget for each level of improvement. For each step of improvement the needed resources should be computed and if after each step enough resources were available, the approach would be repeated and a sequence of $\mathrm{CNs}, W_{C P i_{S E Q}}$, would be the result. In some cases, especially for some manufacturers with non-mass production where the cost of changing production line is not significant, they can actually produce and sell a limited number of products for each step with a discounted price, and then they can collect the feedback and follow the same approach to obtain a sequence of CNs priorities. Obtaining a sequence of customer needs provides the company with a sequence of $W_{A N P} \mathrm{~S}$, which are shown by $\mathrm{W}_{\mathrm{ANP}}{ }_{\mathrm{SEQ}}$.

$$
\begin{aligned}
W_{C P r i_{S E Q}} & =\left[\begin{array}{ccccc}
e_{11} & \ldots & \ldots & \ldots & e_{1 k} \\
\vdots & . & . & . & \vdots \\
: & . & . & . & : \\
e_{n 1} & \ldots & \ldots & \ldots & e_{n k}
\end{array}\right] \\
W_{A N P_{S E Q}} & =\left[\begin{array}{ccccc}
f_{11} & \ldots & \ldots & \ldots & f_{1 k} \\
: & . & . & . & : \\
\vdots & . & . & . & \vdots \\
f_{m 1} & \ldots & \ldots & \ldots & f_{m k}
\end{array}\right]
\end{aligned}
$$


Array $\mathrm{e}_{\mathrm{ij}}$ presents the priority level of $\mathrm{i}^{\text {th }} \mathrm{CN}$ at $\mathrm{j}^{\text {th }}$ time of obtaining a set of $\mathrm{CNs}$ and array $\mathrm{f}_{\mathrm{ij}}$ presents the priority of $\mathrm{i}^{\text {th }} \mathrm{PR}$ at $\mathrm{j}^{\text {th }}$ time. Therefore, the first level of improvement should be done considering the first column of $\mathrm{W}_{\mathrm{ANP}} \mathrm{SEQ}$, the second level considering the second column, and so on. Following this sequence is very important because the improvement process might be suddenly stopped for any seen or unforeseen reasons. The proposed strategies might seem to be timely, long, and tedious, but this is based on the principles of continuous improvement. The results of this approach are helpful and can be used for several areas of decision making. One of these areas is supplier selection process.

\subsection{Supplier selection}

The problem is which supplier should be selected to obtain the highest level of customer satisfaction. The parameters and specifications of final products depend on the raw materials that suppliers are delivering. Since the product parameters can be influenced by different raw materials, it is possible to connect them. This can be done by gathering information about the suppliers and the quality of their raw materials through forming cross-functional teams. After that, a matrix presenting the strength of the relations between each supplier with each product parameter is possible to form. After connecting this matrix to the hybrid-QFD, by changes in priorities of CNs, the suggested best supplier may change. There is a different cost for each level of improvement, some steps are more costly and some are less. To include the costs of each step of improvement as a determining factor in the supplier selection process, the following steps need to be followed.

1-The columns of $W_{A N P}$ should be multiplied by cost ratio of step i, $k_{i}$

$$
C_{W A N P s t_{i}}=k_{i} \times\left[\begin{array}{c}
f_{1 i} \\
\vdots \\
: \\
f_{m i}
\end{array}\right]=\left[\begin{array}{c}
k_{i} f_{1 i} \\
\vdots \\
\vdots \\
k_{i} f_{m i}
\end{array}\right]
$$

$k_{i}$ : an index representing how costly $i^{\text {th }}$ level is

Each weight, $k_{i}$, is a normalized value which presents how costly step $i$ of the improvement process is. For example; if there were three steps of improvement and step two was twice as costly as compared to step one and step three was 0.7 as costly as compared to step one, the weights would be ; $\mathrm{k}_{1}=$ $0.270 ; \mathrm{k}_{2}=0.541 ; \mathrm{k}_{3}=0.189$

2- Arrays of each resulted column must be divided by the summation of the ratios of the previous columns

$j^{\text {th }}$ column of $W_{\text {Step }}=\frac{1}{\sum_{i=1}^{j} k_{i}} \sum_{i=1}^{j} C_{W \text { ANP } s t_{i}}$

3-Forming $W_{\text {Steps }}$

It can be formed by placing the resulted columns in a matrix as below.

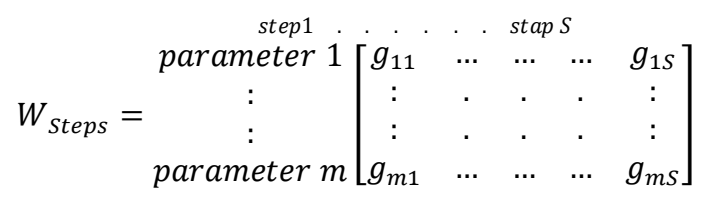

s: last step of improvement plan

A matrix showing the relations between suppliers and PRs, as explained previously, must be formed. 


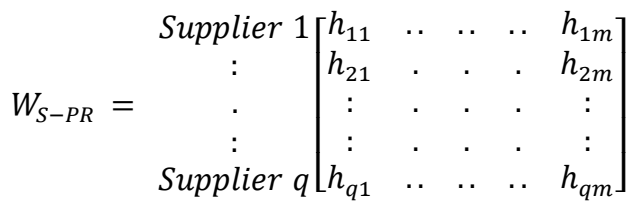

$q$ : the number of suppliers

$m$ : the number of parameters

$h_{i j}$ : the positive effects on $j^{\text {th }}$ parameter by having $i^{\text {th }}$ supplier in compare to the others

And finally, $W_{\text {supplier } W e i g h t s}$ or $W_{S W}$ is resulted.

$$
\begin{aligned}
& W_{S W}=W_{S-P R} \times W_{\text {Steps }}
\end{aligned}
$$

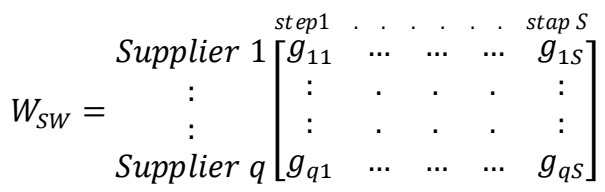

The best supplier in each step is the one with the greatest number in that column. This means when the company decides to improve the quality to pass the $j^{\text {th }}$ step of improvement, the supplier with the greatest $\mathrm{g}_{\mathrm{ij}}\left(\mathrm{g}_{\mathrm{ij}} ; \forall i=1,2, \ldots, q\right)$ must be selected. The results create a new construction for the HOQ that is flexible in confronting changes in customer needs.

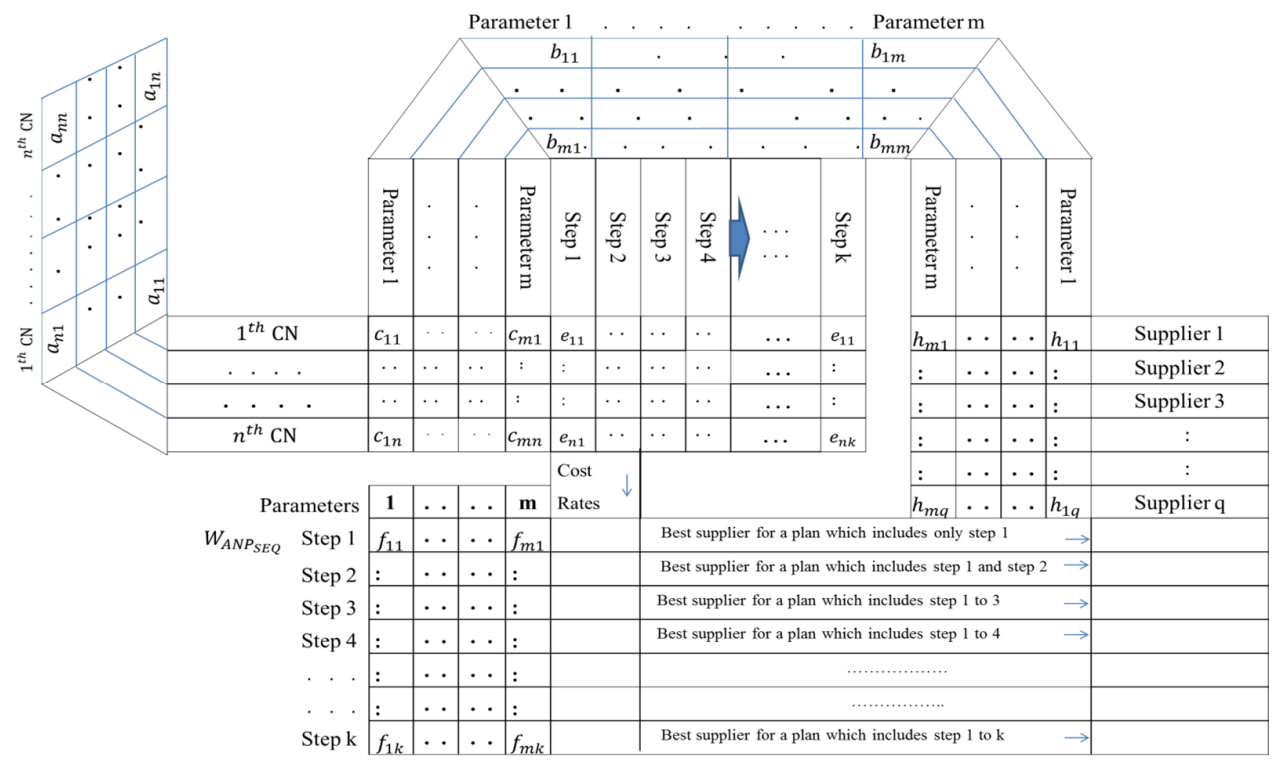

Fig. 1. HOQ in a hybrid-QFD for the Supplier Selection process

A new construction for the HOQ to allocate all the above steps is designed. This new form of the HOQ in comparison to previous forms has the following advantages. First, it accommodates uncertainty in CNs other than the interrelations between CNs and PRs as they are shown by steps 1 to $\mathrm{k}$. Second, it accommodates the resulted changes in the priorities of PRs as are shown by $W_{A N P}$ step 1 to $\mathrm{k}$. Third, it relates PRs to Suppliers' qualifications at the left side of the figure. Fourth, it includes selected supplier for each step as they are presented at the bottom of the figure.

\section{An illustrative simple example}

This example is designed to follow the exact steps of the above methodology. First, the previous methodology is examined (simple ANP-QFD) and then it is developed to a hybrid-QFD. There are six 
potential suppliers and one must be selected. For this purpose, first $\mathrm{W}_{\mathrm{ANP}}$ is computed, and then the sequences of CNs during the improvement plan is acquired and the best supplier is selected.

\section{1 computing $W_{A N P}$}

At first, the information from customers is collected. The more successful a company is in gathering the information and finding the relations, the more accurate the priorities of PRs are found. In order to keep the example simple, the case is restricted to a few CNs and PRs. The cross functional team considering the interviews, can find the priority of CNs. The priority of CNs can be quantified, normalized, and expressed as below.

$W_{\text {Customer Priritization }}=W_{\text {CPri }}=\left[\begin{array}{c}\text { Reliable } \\ \text { Easy to hold } \\ \text { Light weight } \\ \text { Easy to use }\end{array}\right]=\left[\begin{array}{c}0.162 \\ 0.243 \\ 0.189 \\ 0.405\end{array}\right]$

The effects of these elements on each other with respect to each of them must be evaluated. The results of the pairwise comparisons form tables such as the presented table below.

Table 1

The relations among the CNs with respect to the light weight

\begin{tabular}{lllll}
\hline With respect to Light Weight & Easy to hold & Light weight & Easy to use & Relative importance weight \\
\hline Easy to hold & 1 & 0.111 & 0.2 & 0.053 \\
Light weight & 9 & 1 & 8 & 0.786 \\
Easy to use & 5 & 0.125 & 1 & 0.161 \\
\hline
\end{tabular}

The relative importance weights of the elements are computed and placed in the last column of the Table 1. By moving the results (last columns) into one table, the second needed matrix is formed as below.

$W_{\text {CNN }}=\left[\begin{array}{ccll}0.591 & 0.212 & 0 & 0.062 \\ 0.336 & 0.489 & 0.053 & 0.137 \\ 0 & 0.260 & 0.786 & 0.286 \\ 0.073 & 0.038 & 0.161 & 0.515\end{array}\right]$

The product requirement must also be explored. It is assumed that the product has four characteristics: electronic components, plastic components, automatic functions, and ergonomic design of the product. They are shown by parameter A, B, C, and D. There are also interdependencies between these parameters which must be identified with respect to each parameter as below.

\section{Table 2}

The internal relations of parameters with respect to parameter $\mathrm{B}$

\begin{tabular}{lllll}
\hline With respect to Parameter B & A & B & D & Relative importance weight \\
\hline Parameter A & 1 & 0.5 & 3 & 0.303 \\
Parameter B & 2 & 1 & 3 & 0.549 \\
Parameter D & 0.333 & 0.333 & 1 & 0.148 \\
\hline
\end{tabular}

Three more tables, comparing the PRs with respect to each of the other three PRs must be formed. The last columns of those tables build the third needed matrix.

$W_{P R R}=\left[\begin{array}{cccc}0.400 & 0.303 & 0.221 & 0.121 \\ 0.200 & 0.549 & 0 & 0.103 \\ 0.334 & 0 & 0.699 & 0.265 \\ 0.066 & 0.148 & 0.079 & 0.511\end{array}\right]$

The PRs also have relations with respect to each $\mathrm{CN}$. The relations with respect to light weight are presented in Table 3. 
Table 3

The relations between the PRs with respect to light weight

\begin{tabular}{lcccc}
\hline With respect to light weight & A & B & D & Relative importance weight \\
\hline Parameter A & 1 & 0.111 & 2 & 0.147 \\
Parameter B & 9 & 1 & 3 & 0.724 \\
Parameter D & 0.5 & 0.333 & 1 & 0.133 \\
\hline
\end{tabular}

Therefore, the fourth needed matrix forms.

$W_{P R-C N}=\left[\begin{array}{cccc}0.447 & 0 & 0.147 & 0.210 \\ 0.202 & 0.364 & 0.724 & 0 \\ 0.291 & 0.176 & 0 & 0.468 \\ 0.060 & 0.460 & 0.133 & 0.322\end{array}\right]$

To have the prioritized CNs affected by the interdependencies of CNs, $W_{C N N}$ must be multiplied by $W_{C P r i}$.

$W_{2_{-} C P r i}=W_{C N N} \times W_{C P r i}$

$W_{2_{-} C P r i}=\left[\begin{array}{l}0.173 \\ 0.238 \\ 0.313 \\ 0.275\end{array}\right]$

This is presenting the CNs affected by all the interdependencies between themselves. To see how the CNs are affected by the PRs, $W_{P R R}$ must be multiplied by $W_{P R-C N}$.

$$
\begin{aligned}
& W_{2_{-} P R-C N}=W_{P R R} \times W_{P R-C N} \\
& W_{2_{-} P R-C N}=\left[\begin{array}{llll}
0.322 & 0.224 & 0.340 & 0.226 \\
0.197 & 0.231 & 0.410 & 0.075 \\
0.369 & 0.245 & 0.085 & 0.483 \\
0.112 & 0.300 & 0.165 & 0.216
\end{array}\right]
\end{aligned}
$$

Each array in this matrix is connecting the PRs to CNs considering the inner relations of the elements. Now that both $W_{2 \_P R-C N}$ and $W_{2 \_C P r i}$ are obtained, a matrix representing the prioritizations of PRs by multiplying these two matrices can be achieved.

$W_{A N P}=W_{2_{-} P R-C N} \times W_{2_{-} C P r i}$

$W_{A N P}=\left[\begin{array}{l}0.278 \\ 0.238 \\ 0.281 \\ 0.202\end{array}\right]$

This is the translation of CNs into PRs considering all the affecting elements. Based on this matrix, the parameters must be considered for improvement with this priority; C, A, B, and finally D.

\section{2 improvement plans and changing priorities in CNs}

In most of previous papers, it is assumed that improvement must be planned based on $W_{A N P}$, but since $W_{A N P}$ is formed based on the CNs, it may change within the improvement process as CNs change. As it was explained in the methodology, $W_{C P r i_{S E Q}}$ must be acquired based on the strategy that a company chooses to obtain the set of CNs. It is assumed that the priorities of CNs for seven steps of improvement are obtained as below. 
Table 4

The priority of CNs in seven steps of improvement

\begin{tabular}{llllllll}
\hline & Step 1 & Step 2 & Step 3 & Step 4 & Step 5 & Step 6 & Step 7 \\
\hline Reliable & 0.162 & 0.476 & 0.017 & 0.154 & 0.309 & 0.385 & 0.138 \\
Easy to hold & 0.243 & 0.286 & 0.309 & 0.231 & 0.432 & 0.231 & 0.414 \\
Light weight & 0.189 & 0.190 & 0.663 & 0.154 & 0.185 & 0.23 & 0.103 \\
Easy to use & 0.405 & 0.048 & 0.011 & 0.461 & 0.074 & 0.154 & 0.345 \\
\hline
\end{tabular}

\begin{tabular}{|c|c|c|c|c|c|c|c|}
\hline \multirow{4}{*}{$W_{C P r i_{S E Q}}=$} & 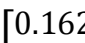 & 0.476 & 0.017 & 0.154 & 0.309 & 0.385 & 0.1 \\
\hline & 0.2 & 0.286 & 0.309 & 0.231 & 0.432 & 0.231 & 0. \\
\hline & 0.18 & 0.190 & 0.663 & 0.154 & 0.185 & 0.23 & 0.103 \\
\hline & & & & & & & \\
\hline
\end{tabular}

So $W_{A N P_{S E Q}}$ is computed below.

$W_{\text {ANPSEQ }}=\left[\begin{array}{lllllll}0.278 & 0.284 & 0.296 & 0.276 & 0.283 & 0.284 & 0.276 \\ 0.238 & 0.241 & 0.300 & 0.233 & 0.250 & 0.242 & 0.239 \\ 0.281 & 0.280 & 0.208 & 0.288 & 0.266 & 0.279 & 0.278 \\ 0.202 & 0.195 & 0.196 & 0.203 & 0.201 & 0.195 & 0.207\end{array}\right]$

Matrix (30) shows the sequence of the priorities in PRs in each step. The improvement must be planned based on the priority shown in the first column, and then consumed and remained resources must be checked. After completing the first step, the improvement plan continues to the second step. Before starting a step, the resources must be checked and if there are still enough resources, that step starts, otherwise it has to be stopped. It is seen in matrix (30), the first priorities are changing. One parameter might be the most important parameter, but only for a part of improvement process (Table 5).

\section{Table 5}

The first priorities of PRs in seven steps of improvement plan

\begin{tabular}{llllllll}
\hline & Step 1 & Step 2 & Step 3 & Step 4 & Step 5 & Step 6 & Step 7 \\
\hline First priority & C & A & B & C & A & A & C \\
\hline
\end{tabular}

\subsection{Supplier Selection}

As mentioned earlier, there are six potential suppliers, but one must be selected. It is assumed that buying from each of them can improve some PRs. The suppliers are compared to each other and the results are shown in a normalized table shown in Table 6.

Table 6

Normalized table of effects of choosing each supplier on PRs of final product

\begin{tabular}{lcccc}
\hline & Parameter A & Parameter B & Parameter C & Parameter D \\
\hline Supplier O & 0.27972 & 0.173913 & 0.051546 & 0.202703 \\
Supplier P & 0.104895 & 0.217391 & 0.164948 & 0.246622 \\
Supplier Q & 0.129371 & 0.043478 & 0.371134 & 0.118243 \\
Supplier R & 0.244755 & 0.043478 & 0.329897 & 0.033784 \\
Supplier S & 0.034965 & 0.304348 & 0.041237 & 0.135135 \\
Supplier T & 0.206294 & 0.217391 & 0.041237 & 0.263514 \\
\hline
\end{tabular}

Therefore, a $6 \times 4$ matrix ( $\left.\mathrm{W}_{\mathrm{S}-\mathrm{PPR}}\right)$ must be formed based on the above table. It is assumed that the cost of improvement for each of seven steps in comparison to step one is estimated or computed as Table 7. This table can be computed by teams, which include professional of design, engineering, and accountancy sections.

Table 7

A comparison of how costly seven steps of improvement would be

\begin{tabular}{lccccccc}
\hline & Step 1 & Step 2 & Step 3 & Step 4 & Step 5 & Step 6 & Step 7 \\
\hline Costs of improving & 1 & 0.3 & 1 & 8 & 1.1 & 0.9 & 7.5 \\
Weights & 0.0426 & 0.0128 & 0.0426 & 0.3404 & 0.0468 & 0.0383 & 0.3191 \\
\hline
\end{tabular}


Table 8 is the priorities in PRs in seven level of improvement affected by how costly the steps are. Based on the methodology the columns of $W_{\text {Steps }}$, which are shown in Table 9 , are computed.

\section{Table 8}

$W_{A N P_{S E Q}}$ affected by cost rates of the steps in table 7

\begin{tabular}{llllllll}
\hline Weighted preference & Step 1 & Step 2 & Step 3 & Step 4 & Step 5 & Step 6 & Step 7 \\
\hline Parameter A & 0.0118 & 0.0036 & 0.0126 & 0.0941 & 0.0132 & 0.0109 & 0.0880 \\
Parameter B & 0.0101 & 0.0031 & 0.0127 & 0.0794 & 0.0117 & 0.0093 \\
Parameter C & 0.0120 & 0.0036 & 0.0089 & 0.0979 & 0.0125 & 0.0107 \\
Parameter D & 0.0086 & 0.0025 & 0.0083 & 0.0690 & 0.0094 & 0.0075 \\
\hline
\end{tabular}

Table 9

Columns of $W_{\text {Steps }}$

\begin{tabular}{lccccccc}
\hline & $\mathbf{1}^{\text {th }}$ Column & $\mathbf{2}^{\text {th }}$ Column & $\mathbf{3}^{\text {th }}$ Column & $\mathbf{4}^{\text {th }}$ Column & $\mathbf{5}^{\text {th }}$ Column & $\mathbf{6}^{\text {th }}$ Column & $\mathbf{7}^{\text {th }}$ Column \\
\hline Parameter A & 0.2778 & 0.2793 & 0.2866 & 0.2786 & 0.2790 & 0.2793 & 0.2780 \\
Parameter B & 0.2381 & 0.2388 & 0.2652 & 0.2404 & 0.2414 & 0.2414 & 0.2405 \\
Parameter C & 0.2815 & 0.2811 & 0.2495 & 0.2792 & 0.2779 & 0.2780 & 0.2781 \\
Parameter D & 0.2017 & 0.2001 & 0.1983 & 0.2017 & 0.2016 & 0.2012 & 0.2034 \\
\hline
\end{tabular}

So, $W_{S W}$ is resulted below.

$W_{S W}=W_{S-P P R} \times W_{\text {Steps }}$

$W_{S-P P R}=\left[\begin{array}{llll}0.2797 & 0.1739 & 0.0515 & 0.2027 \\ 0.1049 & 0.2174 & 0.1649 & 0.2466 \\ 0.1294 & 0.0435 & 0.3711 & 0.1182 \\ 0.2448 & 0.0435 & 0.3299 & 0.0338 \\ 0.0350 & 0.3043 & 0.0412 & 0.1351 \\ 0.2063 & 0.2174 & 0.0412 & 0.2635\end{array}\right]$

$W_{\text {Steps }}=\left[\begin{array}{lllllll}0.2778 & 0.2793 & 0.2866 & 0.2786 & 0.2790 & 0.2793 & 0.2780 \\ 0.2381 & 0.2388 & 0.2652 & 0.2404 & 0.2414 & 0.2414 & 0.2405 \\ 0.2815 & 0.2811 & 0.2495 & 0.2792 & 0.2779 & 0.2780 & 0.2781 \\ 0.2017 & 0.2001 & 0.1983 & 0.2017 & 0.2016 & 0.2012 & 0.2034\end{array}\right]$

\begin{tabular}{|c|c|c|c|c|c|c|c|}
\hline 0 & 0.17450 & 0.17470 & 0. 17934 & 0.17502 & 0.17521 & 0.17523 & 0.17515 \\
\hline$P$ & 0.17706 & 0.17692 & 0.17777 & 0.17728 & 0.17731 & 0.17725 & 0.17747 \\
\hline & 0.17459 & 0.17448 & 0.16464 & 0.17396 & 0.17358 & 0.17359 & 0.17367 \\
\hline$R$ & 0.17801 & 0.17821 & 0.17068 & 0.17756 & 0.17728 & 0.17736 & 0.17710 \\
\hline$S$ & 0.12103 & 0.12107 & 0.12782 & 0.12168 & 0.12192 & 0.12189 & 0.12187 \\
\hline$T$ & 0.17381 & 0.17385 & 0.17932 & 0.17440 & 0.17462 & 0.17459 & لـ 0.17469 \\
\hline
\end{tabular}

Considering matrix 34, one supplier, which is the best based on a specific quality improvement plan of a company may change by changing the company's plans. For instance, when the company decides to improve the quality of the product for three steps, the suggested supplier by this methodology is supplier $O$ while this supplier is not the best for an improvement plan for two or four steps of improvement. Changing the suppliers frequently is not favorable for most companies. In those cases, the company must decide on the improvement plan prior to the selection process. It must be determined that up to which level of improvement the company has plan to improve (usually based on the available needed resources), and then considering that, the best supplier for the company must be selected. It is obvious that if the company wanted to improve, e.g., for five levels, $\mathrm{W}_{\mathrm{ANP}}$ must be considered with at least its first five columns. The results of this example are represented and placed in the suggested new form of the HOQ as the main tool of the hybrid-QFD approach in supplier selection process. 


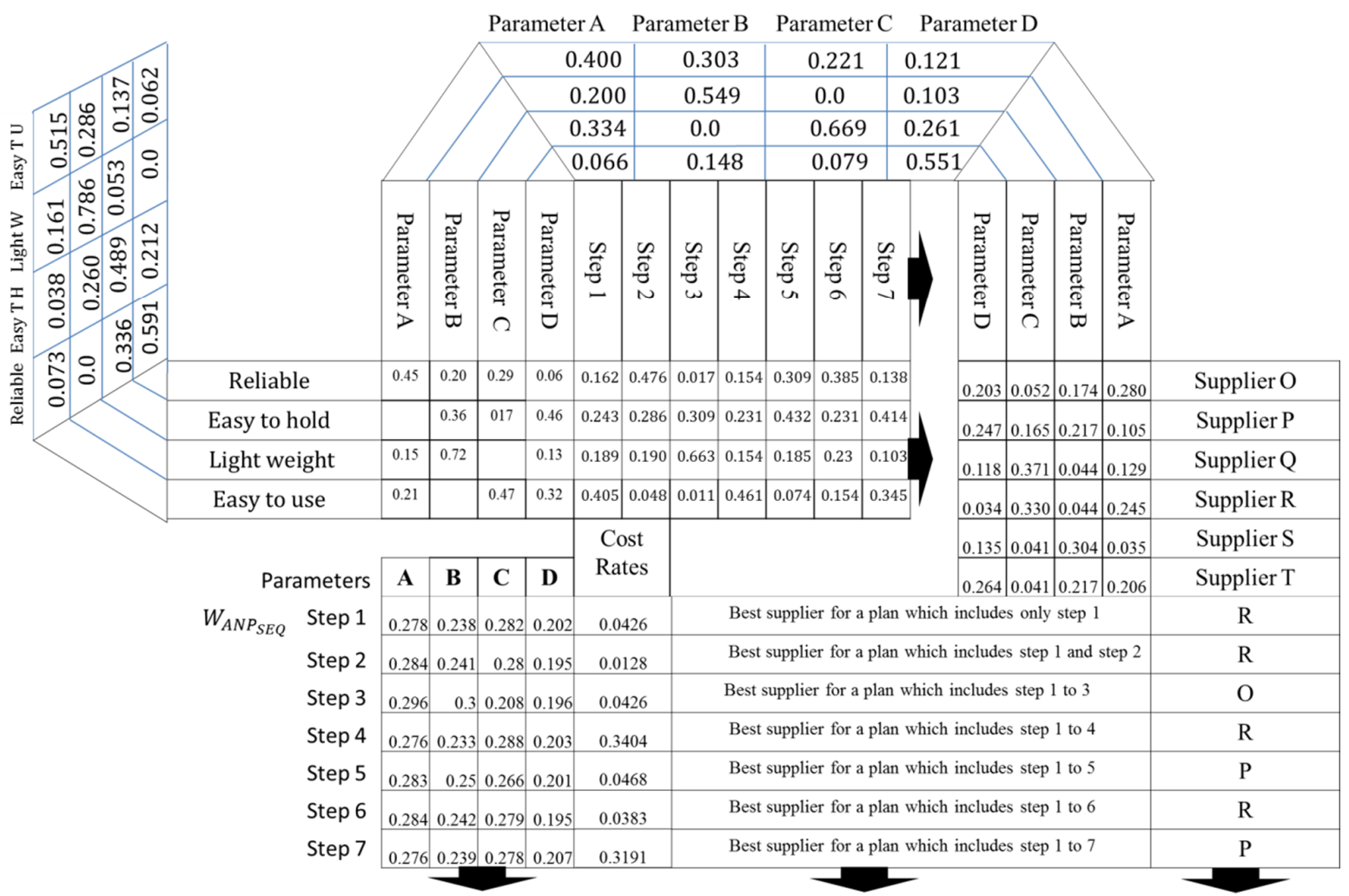

Fig. 2. The hybrid-QFD for the supplier selection process (the example)

\section{Discussion}

Supplier selection is one of the challenging decisions in operations management. There are no successful companies working with incompetence suppliers. A bad selection of suppliers hurts the quality of the final product of a company. Suppliers contribute significantly in successes or failures of a company. The importance of supplier selection problem has created numerous papers (Micheli, 2008; Stadtler, 2007; Gonzales et al., 2004), but it is less seen to have the supplier selection process and the priority of the CNs connected. Linking supplier selection process to a hybrid-QFD is accounted as only a solution to the supplier selection process and is placed besides numerous other solutions. Despite the importance of the challenging problem of supplier selection and a variety of suggested solutions, it seems difficult that a paper can come up with a general solution for this problem. One of the most important steps in QFD is collecting the information. Zhang and Wang (2012) say: "The information from the customers can generally be collected through investigation, questionnaire, interviews and telephone survey. Many tools can be used to summarize customer requirements", but this paper strongly suggests face-to-face meetings with customers to increase the accuracy in finding the priorities. Aside from creating cross functional teams, professionals who know how to acquire more accurate information must be employed to acquire more accurate data. These professionals need to know about different aspects of human behaviors. Kuijt et al. (2009) investigate an example about nature of human answers in interviews or questionnaires. They consider the effects of translating CNs into numbers. They expose how all the answers of a customer can be affected by the first number that they assign to the first question. Problems, such as this, necessitate making a team of professionals for this part of the process to minimize the possibilities of any errors.

In this research, the interdependencies between the elements of the HOQ are considered. These interdependencies are evaluated and analyzed in several papers. The interdependencies are considered through applying processes such as the ANP, which is widely used for a variety of purposes (Andronikidis et al., 2009; Saaty, 1999). In most of ANP applications in the HOQ, researchers assume 
that the priority of CNs remain the same during the improvement process, but this paper traces the changes in priority of CNs. It insists that when a company improves the parameters and assigns the resources based on the primary suggested set of CNs, the company may be wasting the resources and time. Even if the customer satisfaction is increasing, the results would be probably less than what they should be. CNs change at some specific points while PRs are being improved. This is natural in our lives. At any time, people look to satisfy one of their needs (the most important one at the moment); as soon as a need starts satisfaction, its priority may change and that specific need might be no longer their first priority. As the customer priority changes, the priority of product parameters may change. These changes must be observed and the resources must be reassigned based on the new priorities of PRs. This methodology attempts to be a guide for companies to obtain competitive advantages through fast responsiveness to the needs and higher quality. Customers are not as loyal as they were in past few decades; they change the brands easily and move from one brand to another. The changes in what they want must be observed and studied properly. To achieve this, even if it is necessary, changing the suppliers to keep the customers happier might be unavoidable. The hybrid-QFD is employed to follow changes in CNs and prevent failure. Steiner (2011) says: "in most cases, the reason of failure has not been a lack of technological capability of the firm, but an incorrect understanding of real customer needs" (Steiner et al., 2011).

By applying the proposed approach, a sequence of priorities of PRs is resulted. Following this sequence is essential. Even if enough budget and resources for improvement processes are available, the decision makers are advised to follow the sequence because unfortunate events may stop the improvement processes. The suggested method is responsive enough to determine the new best supplier as soon as the priority of $\mathrm{CNs}$ changes. Changing suppliers frequently might not be desirable, but as Herbon et al. (2012) say: "Whenever extreme changes mean that a certain supplier cannot meet requirements or that continuing the contract is not worthwhile, the supplier selection process must be reviewed". However, even when a company prefers to have a long-term relationship with a supplier, it is better to know that at any specific level of the performance of the company, which supplier is the best and how much better than the others it is. The benefits might be significant enough for a company to change a supplier or they might be insignificant in compare to having a long-term trustworthy relation.

As the main tool of hybrid-QFD, a new construction for the HOQ is suggested to allocate the data and the results of hybrid supplier selection process. The new form of the HOQ in comparison to previous forms has the following advantages. First, it accommodates possible changes in priorities of CNs besides from interrelations between $\mathrm{CNs}$ and PRs. Second, it accommodates the consequent changes in the priorities of PRs as are shown. Third, it relates PRs to Suppliers' qualifications. Fourth, it determines selected supplier for each step separately. HOQ acts as a translator of hybrid-QFD which considers all the inner and outer relations and assures an accurate translation. The contribution of this paper is as follows. First, it creates a hybrid-QFD by employing a series of CNs instead of a single set. Second, it links the hybrid-QFD to supplier selection. The proposed hybrid-QFD is observant to all the interrelations between the elements. By connecting it to supplier selection problem, the best suppliers considering all the inherent interrelations of hybrid-QFD are selected. Third, it includes the cost of improvement plans as a determining factor in supplier selection process, which is not considered in previous studies.

This paper creates following areas worthy for future studies. First, there is an area of research addressing the problem of tracing the future CNs by employing a statistical model, such as Markov chains, which may be attached to the entrance of the hybrid-QFD to receive, evaluate, and predict the CNs. Second, there is a potential area of research dealing with inclusions and exclusions of CNs. The possibility of inclusion a new CNs or PRs as well as exclusion an old CNs or PRs in the list of CNs or PRs of the hybrid-HOQ can be investigated. Third, other possible extensions of the proposed approach can be studied. This approach can be extended by involving some other factors in the supplier selection 
problem, e.g., different prices of raw materials by the suppliers which add complexity to the proposed approach.

\section{Conclusion}

A hybrid-QFD is designed and examined. HOQ as the main tool of the QFD is developed to accommodate changes of the priority of CNs. It is extended to be applied as a solution to the supplier selection problem. The priority of CNs change because of numerous known and unknown parameters in customer's mind. The customer priority changes while the PRs are being improved and these changes in the priority of the CNs may change the best suggested supplier. A hybrid-QFD can allocate all of these changes. A supplier selection problem is investigated considering; 1-possible changes in customer priority, 2-all the relations and inner relations between customer needs and product parameters, and 3-costs of quality improvement plans. It is observed that a supplier may be the best only for a short period. The suggested suppliers by this approach may change in different steps of improvement process. Changing suppliers might be not desirable for a lot of companies, it may make the entire supply chain nervous, and this is why it is better if the managers decide on the level of improvement first, and then select the best supplier. It is obvious that a $W_{A N P_{S E O}}$ with at least its first " $k$ " columns must be considered for choosing the best supplier for " $k$ " steps of improvement. This paper contributes the previous studies by developing the previous applications of the QFD, by making this combination flexible to receive a sequence of priorities in CNs, creating a hybrid-QFD, and then by connecting the resulted sequence of priorities of PRs to the supplier selection problem to offer a hybridQFD approach to the supplier selection process. Further studies can investigate the possibility of applying a statistical model to compute a proper sequence of customer priorities. In this research, the case was restricted to a situation in which the list of customer needs is the same during the study, but the priority is changing. Further studies can extend this to consider the possible inclusion of new customer needs as well as exclusion of some of them during the improvement process.

\section{References}

Asamoah, D., Annan, J., \& Nyarko, S. (2012). AHP Approach for Supplier Evaluation and Selection in a Pharmaceutical Manufacturing Firm in Ghana. International Journal of Business \& Management, 7(10).

Ayă̆, Z., Samanlioglu, F., \&Büyüközkan, G. (2013). A fuzzy QFD approach to determine supply chain management strategies in the dairy industry. Journal of Intelligent Manufacturing, 24(6), 1111-1122.

Behzadian, M., Hosseini-Motlagh, S. M., Ignatius, J., Goh, M., \& Sepehri, M. M. (2013). PROMETHEE group decision support system and the house of quality. Group Decision and Negotiation, 22(2), 189-205.

Büyüközkan, G., \& Berkol, Ç. (2011). Designing a sustainable supply chain using an integrated analytic network process and goal programming approach in quality function deployment. Expert Systems with Applications, 38(11), 13731-13748.

Cassandra S., Gül O.k., Gülşen A. (2012). Verification of QFD \& K-means based Product Family Size Optimization through ANP: The Viper Case. Industrial and Systems Engineering Research Conference.

Chandra, C., \& Grabis, J. (2003). Impact of supply lead time on supplier selection: an operational perspective. IIE Annual Conference. Proceedings 1-6.

Delice, E. K., \& Güngör, Z. (2009). A new mixed integer linear programming model for product development using quality function deployment. Computers \& Industrial Engineering, 57(3), 906912. 
Dey, S., Kumar, A., Ray, A., \& Pradhan, B. B. (2012). Supplier Selection: Integrated Theory using DEMATEL and Quality Function Deployment Methodology. Procedia Engineering, 38, 35603565.

Ginn, D., \& Zairi, M. (2005). Best practice QFD application: an internal/external benchmarking approach based on Ford Motors' experience. International Journal of Quality \& Reliability Management, 22(1), 38-58.

González, M. E., Quesada, G., \& Monge, C. A. M. (2004). Determining the importance of the supplier selection process in manufacturing: a case study. International Journal of Physical Distribution \& Logistics Management, 34(6), 492-504.

Gremyr, I., \&Raharjo, H. (2013). Quality function deployment in healthcare: a literature review and case study. International journal of health care quality assurance, 26(2), 135-146.

Hauster, J.R., \& Clausing, D. (1988), the house of quality, Harvard business review, 66(3), 63-73

Herbon, A., Moalem, S., Shnaiderman, H., \&Templeman, J. (2012). Dynamic weights approach for offline sequencing of supplier selection over a finite planning horizon. International Journal of Physical Distribution \& Logistics Management, 42(5), 434-463.

Ho, E. S. S. A., Lai, Y. J., \& Chang, S. I. (1999). An integrated group decision-making approach to quality function deployment. IIE transactions, 31(6), 553-567.

Ho, W., Dey, P. K., \& Lockström, M. (2011). Strategic sourcing: A combined QFD and AHP approach in manufacturing. Supply Chain Management, 16(6), 446-461.

Jabbour, A. B. L., \& Jabbour, C. J. (2009). Are supplier selection criteria going green? Case studies of companies in Brazil. Industrial Management \& Data Systems, 109(4), 477-495.

Jiang, J. C., Shiu, M. L., \& Tu, M. H. (2007). Quality function deployment (QFD) technology designed for contract manufacturing. The TQM Magazine, 19(4), 291-307.

Kahraman, C., Cebeci, U., \& Ulukan, Z. (2003). Multi-criteria supplier selection using fuzzy AHP. Logistics Information Management, 16(6), 382-394.

Karsak, E. E., Sozer, S., \& Alptekin, S. E. (2003). Product planning in quality function deployment using a combined analytic network process and goal programming approach. Computers \& industrial engineering, 44(1), 171-190.

Karsak, E. E., \& Ece, M. (2012). An integrated methodology for supplier evaluation and selection using QFD and DEA. Journal of Management \& Engineering Integration, 5(1) 34-42.

Kim, D. (2010). Application of the HoQ framework to improving QoE of broadband internet services. IEEE Network, 24(2), 4

Kim, D. H., \& Kim, K. J. (2009). Robustness indices and robust prioritization in QFD. Expert Systems with Applications, 36(2), 2651-2658.

Kovach, J. Cho, B. R., \& Fredendall, L. D. (2006). Latent benefits and connections within quality function deployment. IIE Annual Conference. Proceedings, , 1-6.

Kuijt-Evers, L. F. M., Morel, K. P. N., Eikelenberg, N. L. W., \& Vink, P. (2009). Application of the QFD as a design approach to ensure comfort in using hand tools: Can the design team complete the House of Quality appropriately?. Applied ergonomics, 40(3), 519-526.

Lin, Y., \& Pekkarinen, S. (2011). QFD-based modular logistics service design. Journal of Business \& Industrial Marketing, 26(5), 344-356.

Andronikidis, A., Georgiou, A. C., Gotzamani, K., \& Kamvysi, K. (2009). The application of quality function deployment in service quality management. The TQM journal, 21(4), 319-333.

Liu, C. H. (2010). A group decision-making method with fuzzy set theory and genetic algorithms in quality function deployment. Quality \& Quantity, 44(6), 1175-1189.

Mayyas, A., Shen, Q., Mayyas, A., Shan, D., Qattawi, A., \& Omar, M. (2011). Using quality function deployment and analytical hierarchy process for material selection of body-in-white. Materials \& Design, 32(5), 2771-2782.

Mehrjerdi, Y. Z. (2010). Quality function deployment and its extensions.International Journal of Quality \& Reliability Management, 27(6), 616-640.

Micheli, G. J. (2008). A decision-maker-centred supplier selection approach for critical supplies. Management Decision, 46(6), 918-932. 
Nazari, A., Salarirad, M. M., \& Bazzazi, A. A. (2012). Landfill site selection by decision-making tools based on fuzzy multi-attribute decision-making method. Environmental Earth Sciences, 65(6), 1631-1642.

Olewnik, A., \& Lewis, K. (2008). Limitations of the House of Quality to provide quantitative design information. International Journal of Quality \& Reliability Management, 25(2), 125-146.

Ordoobadi, S. M. (2012). Application of ANP methodology in evaluation of advanced technologies. Journal of Manufacturing Technology Management,23(2), 229-252.

Ozaki, T., Lo, M. C., Kinoshita, E., \& Tzeng, G. H. (2012). Decision-making for the best selection of suppliers by using minor ANP. Journal of Intelligent Manufacturing, 23(6), 2171-2178.

Özgener, Z. (2003). Quality function deployment: A teamwork approach. Total Quality Management and Business Excellence, 14(9), 969-979.

Pearson, J. N., \& Ellram, L. M. (1995). Supplier selection and evaluation in small versus large electronics firms. Journal of Small Business Management,33(4), 53-65.

Prasad, K. D., Subbaiah, K. V., \& Rao, K. N. (2012). Aligning the competitive strategy with supply chain strategy through QFD. Journal of Advances in Management Research, 9(2), 189-198.

Raharjo, H., Xie, M., \& Brombacher, A. C. (2011). A systematic methodology to deal with the dynamics of customer needs in Quality Function Deployment. Expert Systems with Applications, 38(4), 3653-3662.

Hemaida, R., \& Schmits, J. (2006). An Analytical Approach to Vendor Selection. Industrial Management, 48(3). 18-24.

Saaty, T. L. (1999). Decision making for leaders: the analytic hierarchy process for decisions in a complex world (Vol. 2). RWS publications.

Stadtler, H. (2007). A general quantity discount and supplier selection mixed integer programming model. OR Spectrum, 29(4), 723-744.

Steiner, F., Ihl, C., Piller, F., \& Tarman, R. T. (2011). Embedded Toolkits: Identifying Changing User Needs During Product Usage. Engineering Management Journal, 23(4).

Tidwell, A., \& Sutterfield, J. S. (2012). Supplier selection using QFD: A consumer products case study. The International Journal of Quality \& Reliability Management, 29(3), 284-294.

Tsalatsanis, A., Hozo, I., Vickers, A., \& Djulbegovic, B. (2010). A regret theory approach to decision curve analysis: a novel method for eliciting decision makers' preferences and decisionmaking. BMC Medical Informatics and Decision Making, 10(1), 51.

Weber, C. A., \& Ellram, L. M. (1993). Supplier selection using multi-objective programming: a decision support system approach. International Journal of Physical Distribution \& Logistics Management, 23(2), 3-14.

$\mathrm{Wu}$, L. C. (2009). Supplier selection under uncertainty: a switching options perspective. Industrial Management \& Data Systems, 109(2), 191-205.

Zhang, Z., \& Wang, Y. (2012). A three-dimensional service HOQ based on economic perspective. Kybernetes, 41(5), 725-735. 